NASA Technical Memorandum 104467

AIAA-91-3422

\title{
Coplanar Waveguide Feeds for Phased Array Antennas
}

Rainee N. Simons

Sverdrup Technology, Inc.

Lewis Research Center Group

Brook Park, Ohio

and

Richard Q. Lee

National Aeronautics and Space Administration

Lewis Research Center

Cleveland, Ohio

Prepared for the

Conference on Advanced Space Exploration Initiative Technologies cosponsored by AIAA, NASA, and OAI

Cleveland, Ohio, September 4-6, 1991 


\title{
COPLANAR WAVEGUIDE FEEDS FOR PHASED ARRAY ANTENNAS
}

\author{
Rainee N. Simons \\ Sverdrup Technology, Inc. \\ Lewis Research Center Group \\ Brook Park, Ohio 44142
}

and

Richard Q. Lee

National Aeronautics and Space Administration

Lewis Research Center

Cleveland, Ohio 44135

\begin{abstract}
$\underline{\text { Abstract }}$
This paper presents the design and performance of the following CPW microwave distribution networks for linear as well as circularly polarized microstrip patches and printed dipole arrays: (1) CPW/Microstrip Line feed, (2) CPW/ Balanced Stripline feed, (3) CPW/Slotline feed, (4) GCPW/ Balanced coplanar stripline feed, and (5) CPW/Slot coupled feed. Typical measured radiation patterns are presented, and their relative advantages and disadvantages are compared.

\section{Introduction}

Coplanar waveguide (CPW) is a transmission line which consists of a center strip and a semi-infinite ground plane on either side of it $^{1}$ as shown in Fig. 1. This type of waveguide offers several advantages over conventional microstrip line, namely, it facilitates easy shunt as well as series mounting of active and passive devices; it eliminates the need for wraparound and via holes, and it has a low radiation loss. Another important advantage of $\mathrm{CPW}$ which has recently emerged is that CPW circuits render themselves to fast and inexpensive on-wafer characterization at frequencies as high as $50 \mathrm{GHz}^{2}$ Lastly, since the RF magnetic fields in the CPW are elliptically polarized, ${ }^{3}$ nonreciprocal components such as ferrite circulators and isolators ${ }^{4}$ can be efficiently integrated with the feed network. These as well as other advantages make CPW useful for a MMIC based microwave distribution network. Grounded CPW (GCPW) is a variant of CPW which incorporates an additional ground plane on the back side of the substrate ${ }^{5}$ as shown in Fig. 1. This additional ground plane can serve as a heat sink and provide mechanical strength. In addition, the ground plane serves as a shield between stacked antenna boards to improve isolation.
\end{abstract}

Several CPW fed antennas have been reported in the literature. A GCPW fed coplanar stripline antenna constructed by widening the center strip of the GCPW to form a rectangular patch (Fig. 2(a)) has been reported. ${ }^{6}$ This antenna produces a linearly polarized far field radiation pattern in a direction normal to the plane of the substrate.
CPW fed slot antennas which are the complcment to printed dipole antennas (Fig. 2(b)) have also been reported. ${ }^{7}$ This antenna also radiates in a direction normal to the plane of the substrate.

This paper presents the design and performance of the following CPW microwave distribution networks for linear as well as circularly polarized microstrip patches and printed dipole arrays: (1) CPW/Microstrip Line feed, (2) CPW/ Balanced Stripline feed, (3) CPW/Slotline feed, (4) GCPW/ Balanced coplanar stripline feed, and (5) CPW/Slot coupled feed. Typical measured radiation patterns are presented, and their relative advantages and disadvantages are compared.

\section{CPW Microwave Distribution Network Design}

\section{Coplanar Waveguide/Microstrip Line Feed}

A CPW to microstrip line feed with post coupler ${ }^{8}$ is shown in Fig. 3. The CPW and the microstrip line share a common ground plane that has an aperture. The coupler is formed by a metal post which passes through the aperture connecting the strip conductors of the CPW and the microstrip line. A pair of wire bonds located adjacent to the post tie the CPW ground planes and the microstrip ground planes to a common potential. The diameters of the aperture and the metal post were experimentally optimized to obtain the best insertion loss characteristics. The advantage of this type of feed is that the thickness and relative permittivity of the dielectric substrates for the feed network and the antenna can be independently chosen. This allows the individual components to be optimized for the best performance.

\section{Coplanar Waveguide/Balanced Stripline Feed}

A CPW to balanced stripline feed also makes use of a post coupler ${ }^{9}$ as illustrated in Fig. 4. The mechanical features of the coupler is similar to that described above. This coupler in addition uses a tapered stub to improve the bandwidth of the device. The advantage of this feed is similar to that of the previous example. 


\section{Coplanar Waveguide/Slotine Feed}

A CPW to slotline feed ${ }^{10}$ which uses a nonplanar CPW T-junction is illustrated in Fig. 5. The circuit is formed when a CPW on a separate substrate is placed perpendicular on the CPW of the CPW/Slotline feed network. The advantage of this type of feed is that it eliminates the need for direct connection between the feed line and the feed network of the array module.

\section{Grounded Coplanar Waveguide/Balanced Coplanar Stripline Feed}

Figure 6 shows a GCPW to balanced coplanar stripline feed. ${ }^{11}$ Since the GCPW is an unbalanced structure, the transition to a balanced coplanar stripline requires a balun. ${ }^{12}$ At the unbalanced end, currents of equal magnitudes but opposite direction flow in the center strip conductor 2 and in the ground planes 1 and 3 of the GCPW. At the balanced end, currents of equal magnitude but opposite in direction flow in the strip conductors 2 and 3 of the coplanar stripline. The short circuit placed between conductors 1 and 2 at the balanced end results in an open circuit between the conductors a quarter wavelength away at the unbalanced end forcing all currents to flow between conductors 2 and 3 .

In addition, the balun also provides impedance transformation. This transformation ratio is determined by the characteristic impedance of the coplanar stripline formed by conductors 2 and 3 . This is because all of the microwave energy propagates through this section of the transmission line. The advantage of this type of feed is that it allows construction of end fire arrays which are necessary for building large two-dimensional phased arrays. The disadvantage is that it requires a bond wire to tie conductors 1 and 3 at equal potential which might impact reliability.

\section{Coplanar Waveguide/Slot Coupled Feed}

This circuit is formed by etching a narrow resonant slot in the bottom ground plane of a GCPW. The slot is oriented symmetrically and transverse to the center strip conductor of the GCPW. The advantage of this type of feed is that the microstrip patch antennas can be electromagnetically coupled to the feed through the aperture thus making integration easy.

\section{Coplanar Waveguide Feed System Performance and Antenna Integration}

The measured return loss $\left(\mathrm{S}_{11}\right)$ and insertion loss $\left(\mathrm{S}_{21}\right)$ of the CPW/Microstrip line post coupler is shown in Fig. 7. The return loss and insertion loss are better than 10 and $1 \mathrm{~dB}$, respectively, over a wide band of frequencies extending from 0.045 to $6.5 \mathrm{GHz}$. Figure 8 schematically illus- trates the integration of a rectangular patch antenna with the feed.

The measured return loss $\left(\mathrm{S}_{11}\right)$ and insertion loss $\left(\mathrm{S}_{21}\right)$ of the CPW/Balanced stripline post coupler is shown in Fig. 9. The return loss and insertion loss are better than 17 and $0.25 \mathrm{~dB}$ at the design frequency of $2.2875 \mathrm{GHz}$. Figures 10(a) and (b) present the proof-of-concept model of a seven patch hexagonal circularly polarized (CP) subarray with the above feed system.

The above are typical characteristics of the feeds discussed in the previous section and the characteristics of the other feeds will be presented at the conference.

\section{Far Field Radiation Patterns of the Antennas}

The measured far field radiation pattern of the microstrip patch antennas shown in Fig. 8 are presented in Fig. 11. The radiation is linearly polarized and is parallel to the plane of the antenna.

The measured far field radiation patterns of the $\mathrm{CP}$ subarray shown in Fig. 10 is presented in Fig. 12. These patterns were measured at $2.325 \mathrm{GHZ}$. The on-axis axial ratio for the LHCP is 1.5 and $3 \mathrm{~dB}$ beam widths are $36^{\circ}$ in both planes of the subarray. The gain of the subarray as determined from the beam widths is $13 \mathrm{~dB}$. The measured return loss at the coaxial input port of the subarray is better than $10 \mathrm{~dB}$ at $2.325 \mathrm{GHz}$.

The above are typical measured radiation patterns of the antennas investigated and more results will be presented at the conference.

\section{Conclusions and Discussions}

The paper presents the design and performance of several CPW microwave distribution networks which have potential applications in phased arrays. Typical measured far field radiation patterns of several antennas with the above feeds have been presented and discussed.

\section{$\underline{\text { References }}$}

1. Wen, C.P., "Coplanar Waveguide:A Surface Strip Transmission Line Suitable for Nonreciprocal Gyromagnetic Device Applications," IEEE Transactions on Microwave Theory and Techniques, Vol. MTT-17, No. 12, Dec. 1969, pp. 1087-1090.

2. Jones, K.E., Strid, E.W., and Gleason, K.R., "mm-Wave Wafer Probes Span 0 to $50 \mathrm{GHz}$," Microwave Journal, Vol. 30, No. 4, Apr. 1987, pp. 177-183.

3. Simons, R.N. and Arora, R.K., "Coupled Slot Line Field Components, "IEEE Transactions on Microwave Theory and Techniques, Vol. MTT-30, No. 7, July 1982, pp. 1094-1099. 
4. Koshiji, K. and Shu, E., "Circulators Using Coplanar Waveguide," Electronics Letters, Vol. 22, No. 19, Sept. 11, 1986, pp. 1000-1002.

5. Shih, Y.C. and Itoh, T., "Analysis of Conductor-Backed Coplanar Waveguide," Electronics Letters, Vol. 18, No. 12, June 10, 1982, pp. 538-540.

6. Greiser, J.W., "Coplanar Stripline Antenna," Microwave Journal, Vol. 19, No. 10, Oct. 1976, pp. 47-49.

7. Nesic, A., "Printed Slotted Array Excited by a Coplanar Waveguide," 12th European Microwave Conference Digest, Microwave Exhibitions and Publishers, Kent, England, Sept. 1982, pp. 478-482.

8. Simons, R.N. and Lee, R.Q., "Coplanar Waveguide/Microstrip Probe Coupler and Applications to Antennas, " Electronics Letters, Vol. 26, No. 24, Nov. 22, 1990, pp. $1998 \cdot 2000$.

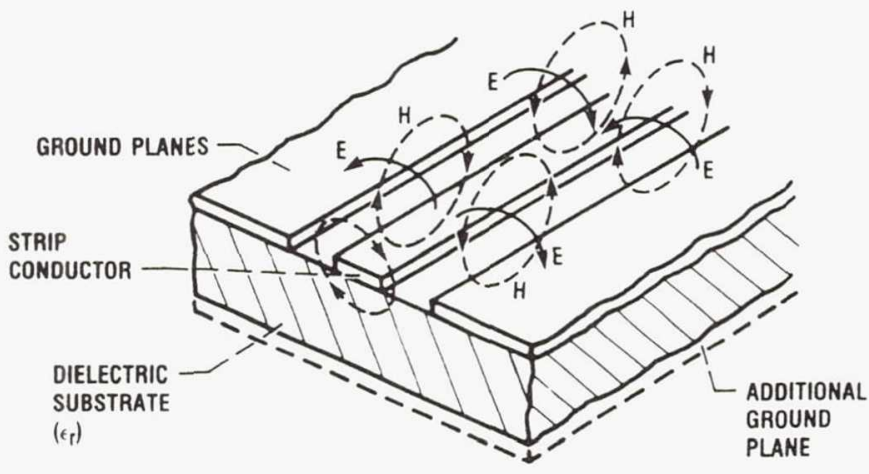

Figure 1.-Schematic illustrating the fields along the coplanar waveguide and the optional lower ground plane.
9. Simons, R.N., Lee, R.Q., and Lindamood, G.R., "A New Coplanar Waveguide/Stripline Feed Network for a Seven Patch Hexagonal CP Subarray," Electronics Letters, Vol. 27, No. 6, March 1991, pp. 533-535.

10. Lee, R.Q. and Simons, R.N., "Electromagnetically Coupled Feed Network for an Array Module of Four Microstrip Elements, 1988 IEEE International Symposium on Antennas and Propagation Symposium Digest, Vol. III, IEEE, 1988, pp. 1018-1021.

11. Simons, R.N., Ponchak, G.E., Lee, R.Q., and Femandez, N.S., "Coplanar Waveguide Fed Phased Array Antenna," 1990 IEEE International Symposium on Antennas and Propagation Symposium Digest, Vol. IV, IEEE, 1990, pp. 1778-1781.

12. DeBrecht, R.E., "Coplanar Balun Circuits for GaAs FET High-Power Push-Pull Amplifiers," 1973 IEEE G-MTT International Microwave Symposium Digest, IEEE, 1973, pp. 309-311.

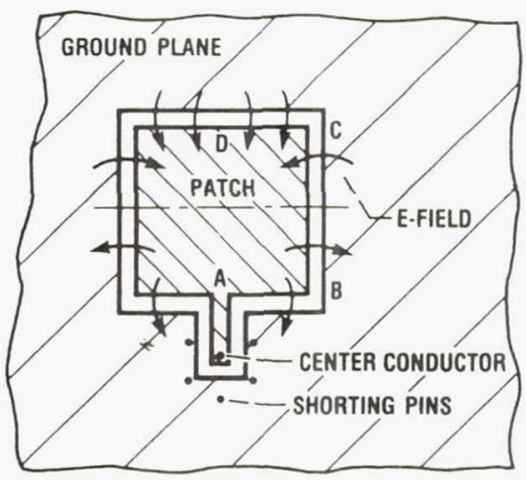

(a) CPW patch antenna.

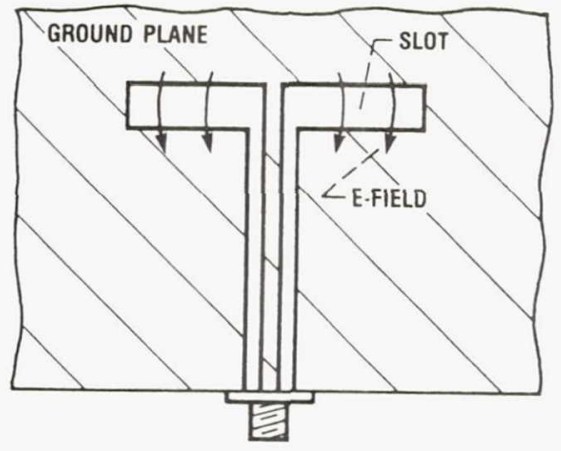

(b) CPW slot antenna.

Figure 2.-Coplanar wave guide antenna. 


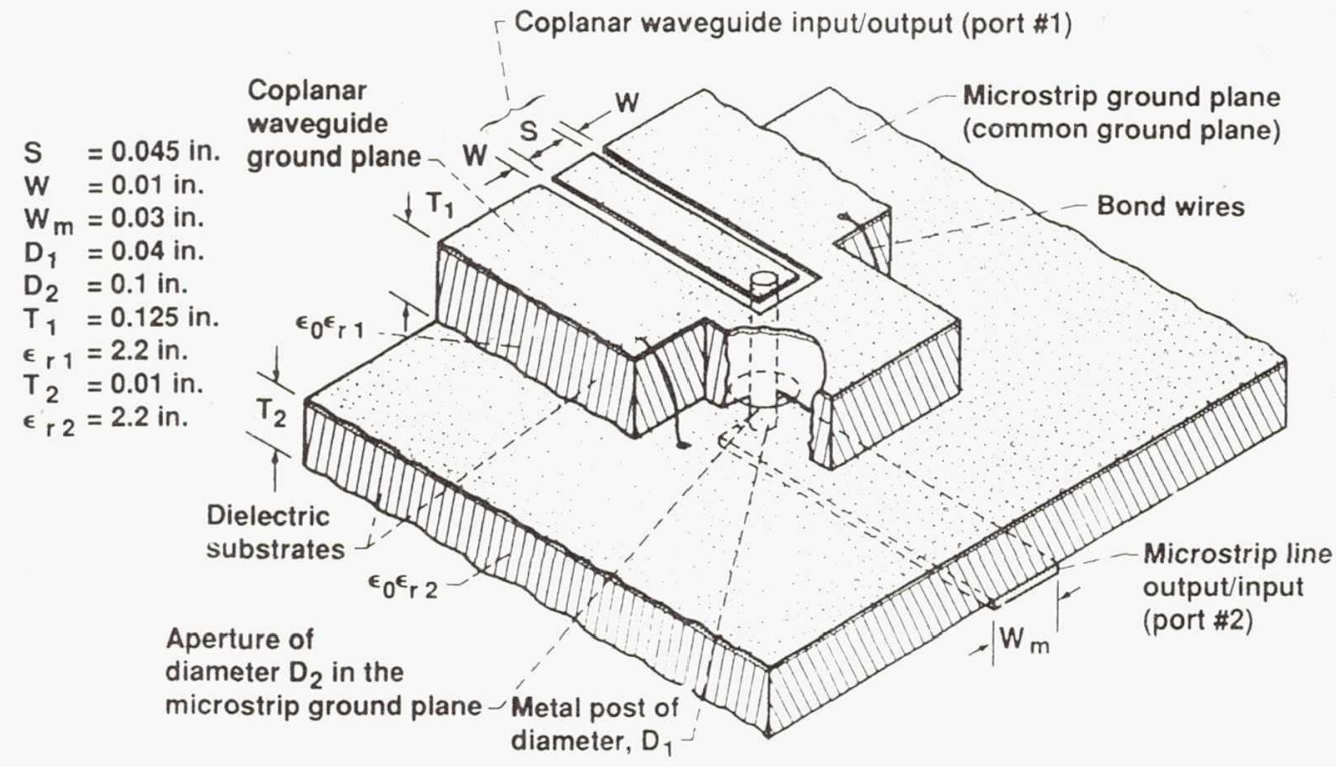

Figure 3.-Schematic of a CPW/microstrip line post coupler feed.

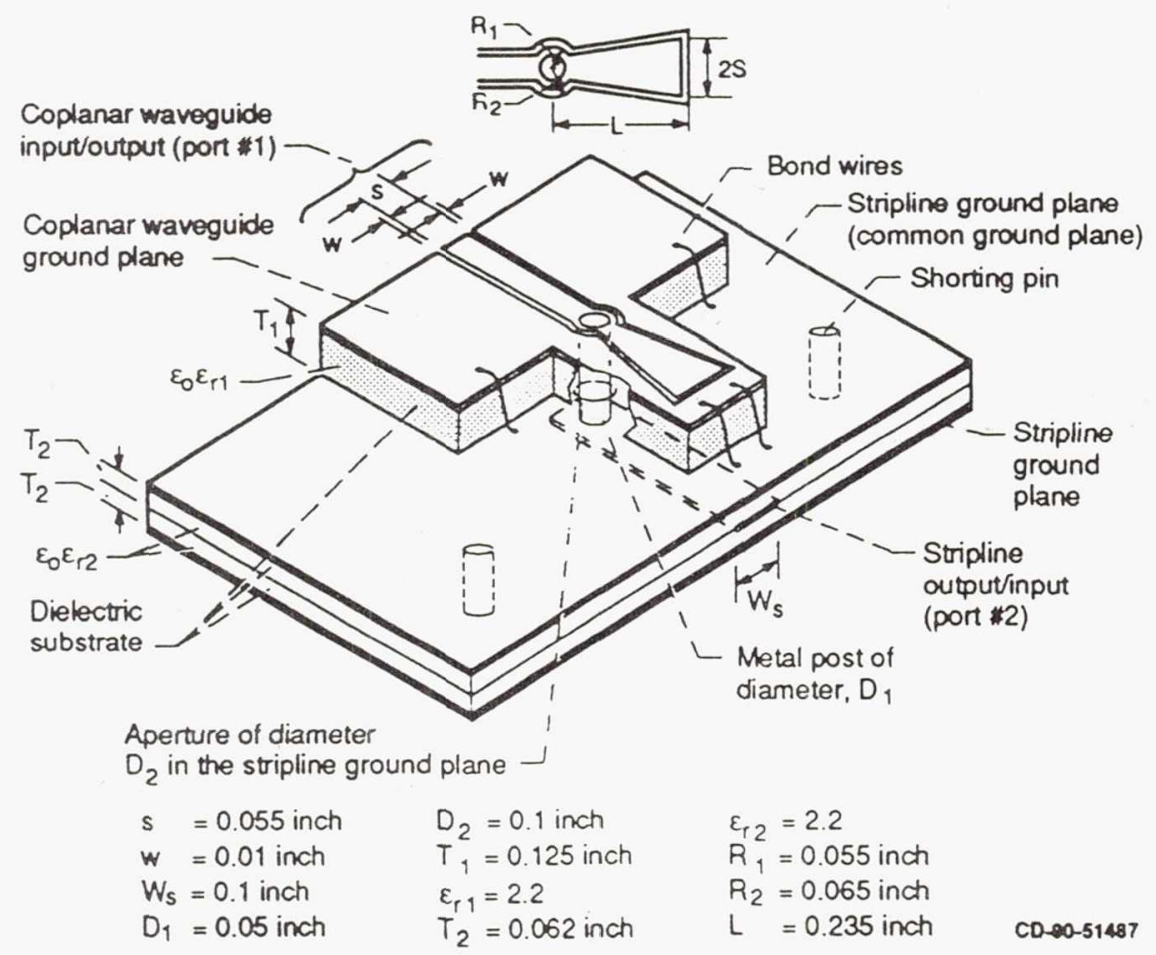

Flgure 4.-Schematic of a CPW/balanced stripline post coupler. 


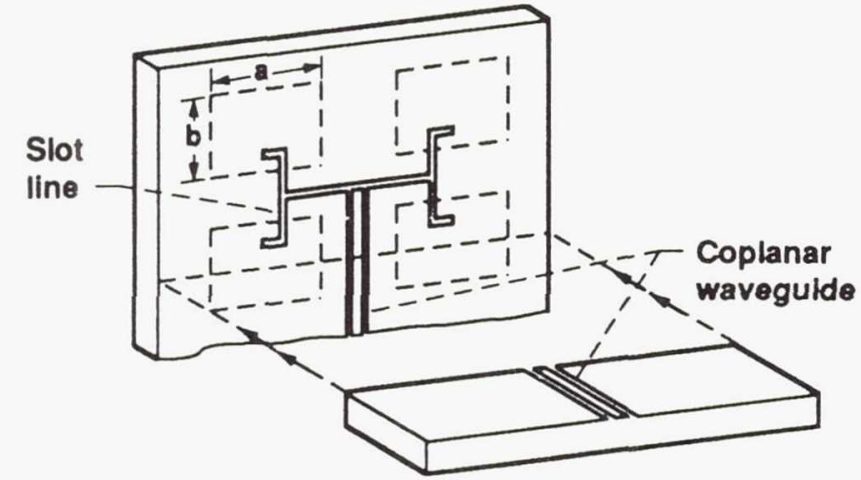

Figure 5.-Schematic of a CPW/slot line feed.

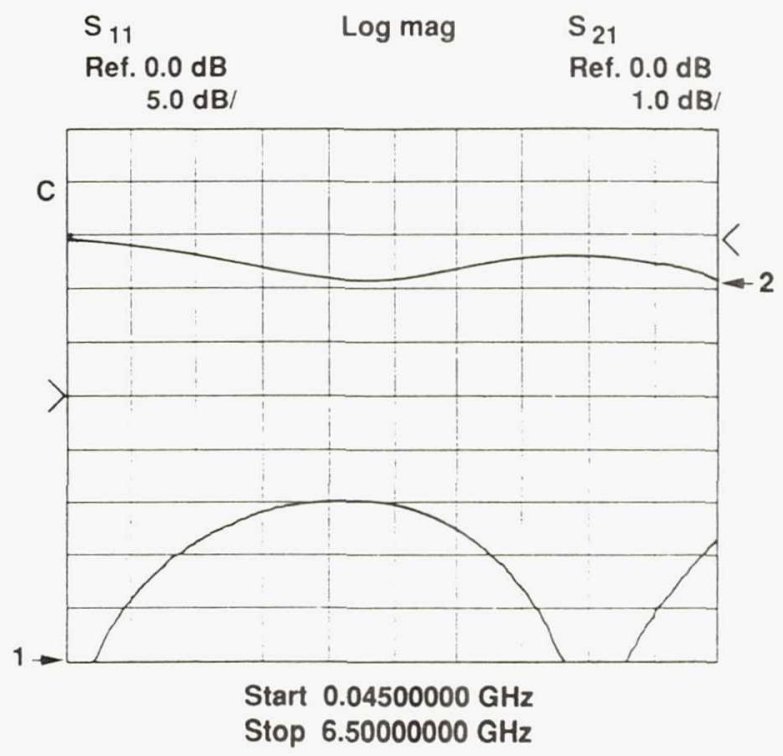

Figure 7.- Measured return loss $\left(\mathrm{S}_{11}\right)$ and insertion loss $\left(S_{21}\right)$ of a CPW/microstrip line post coupler feed.

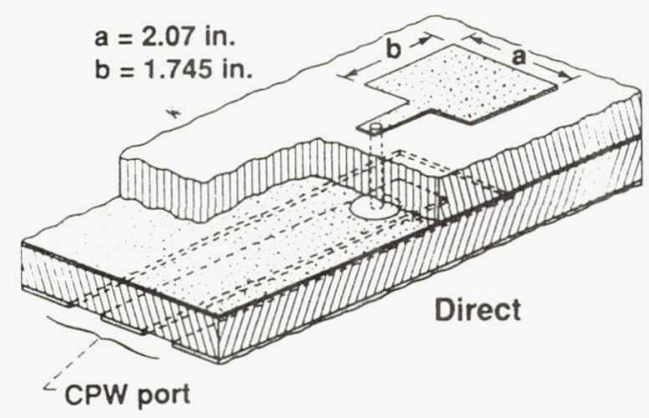

(a) Direct feed.

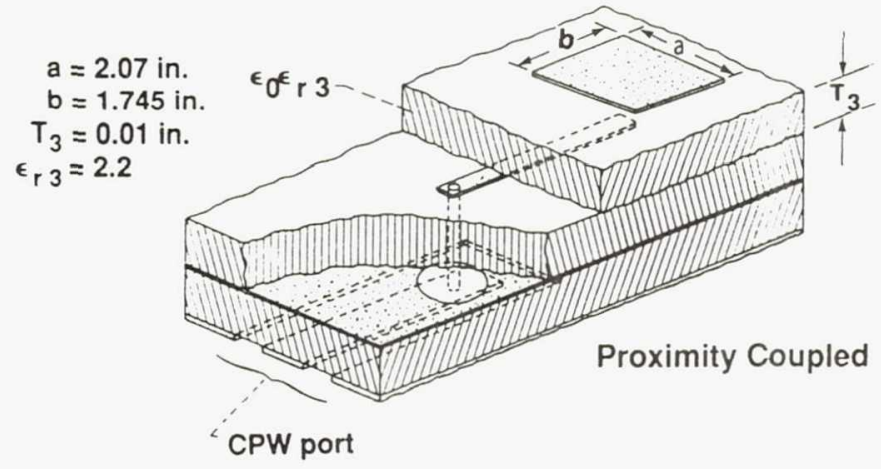

(b) Proximity coupled feed.

Figure 8.-Schematic illustrating the integration of a patch antenna with $\mathrm{CPW} / \mathrm{micros}$ trip feed. 


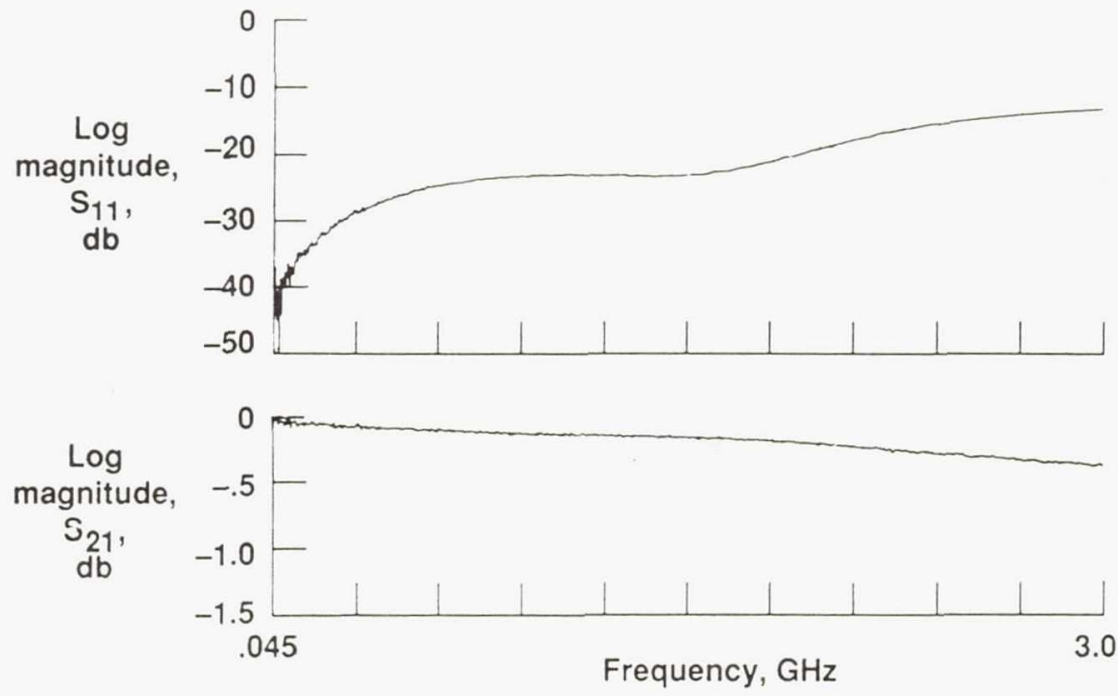

Figure 9.-Measured return loss $\left(\mathrm{S}_{11}\right)$ and insertion loss $\left(\mathrm{S}_{21}\right)$ of a CPW/balanced stripline coupler feed.

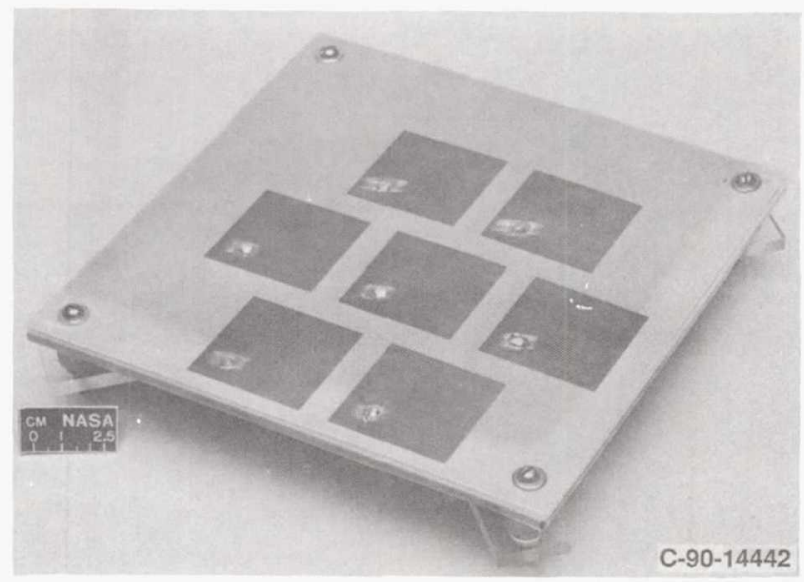

(a) Antenna layer.

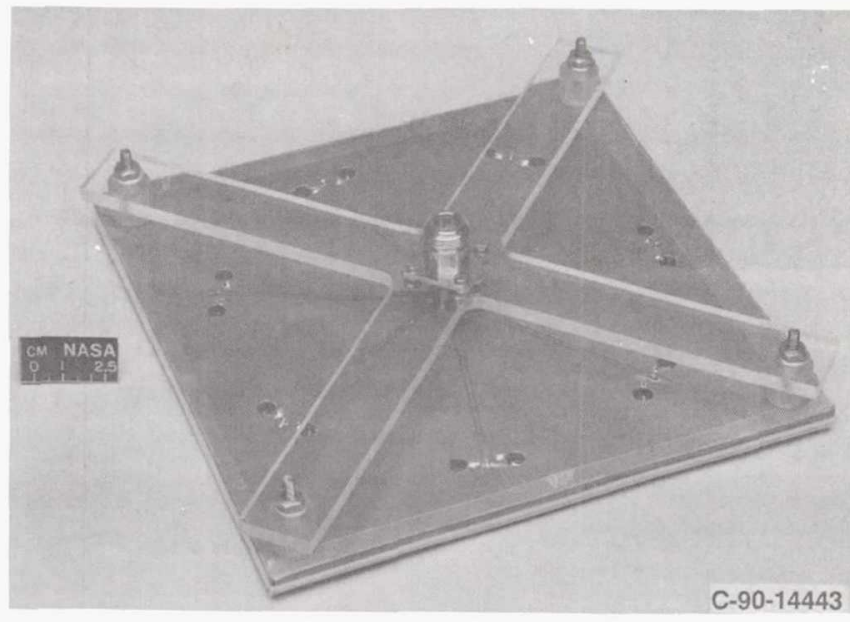

(b) CPW power divider layer.

Figure 10.-Proof-of-concept model of a seven patch hexagonal CP subarray. 


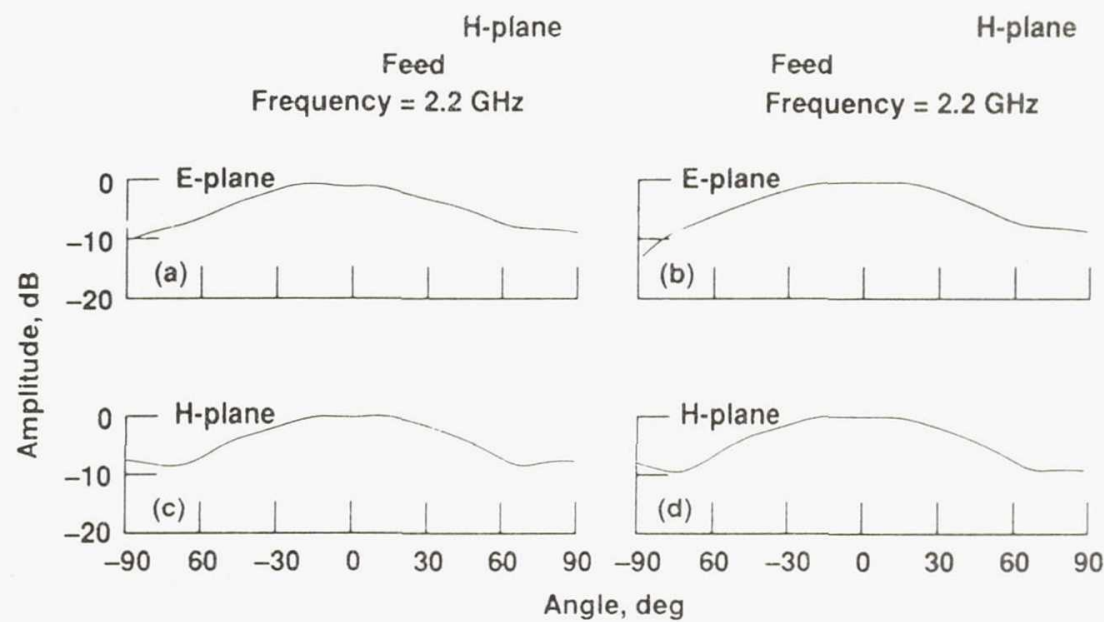

(a) and (c) Antena excited directly by CPW/microstrip feed.

(b) and (d) Antena excited by proximity coupled CPW/microstrip feed.

Figure 11. - Measured far field radiation pattern of the microstrip patch antenna.

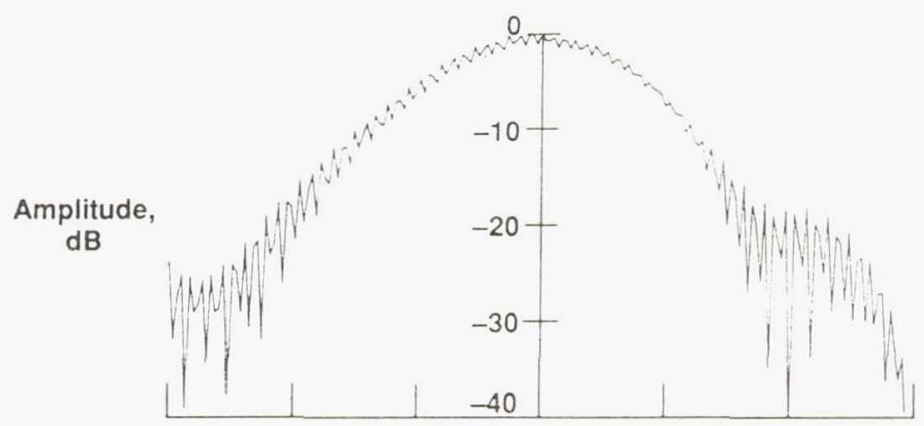

(a) $\phi=0^{\circ}$ plane

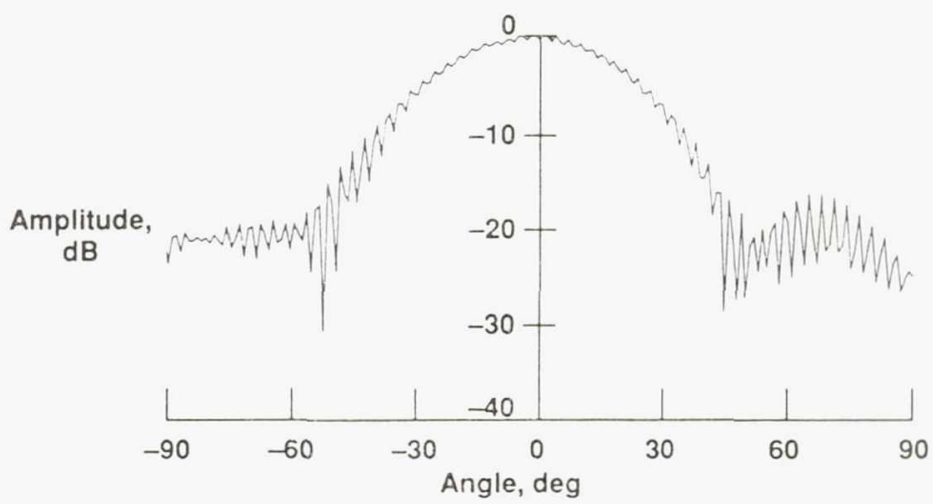

(b) $\phi=90^{\circ}$ plane.

Figure 12.-Measure far field radiation pattern of the subarray. 


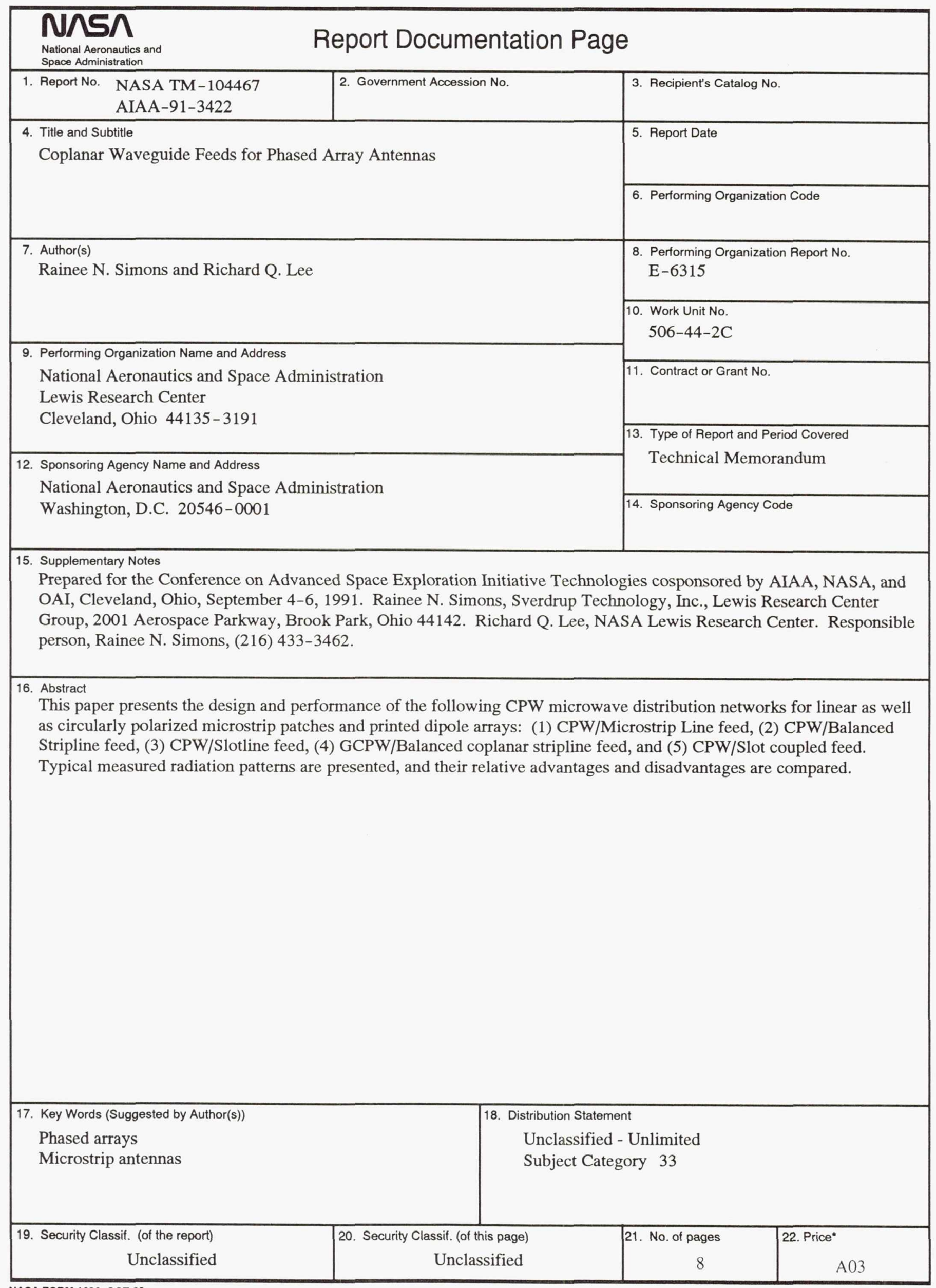

